\title{
8. Moving from the periphery to the inner circle: getting published from your thesis
}

\author{
Sally Jones and Helle Neergaard
}

As a doctoral student you will undoubtedly be met with demands for publication - sooner rather than later. Since you will start out as a novice in the race for publication, you will need some advice on how to get a head start. This chapter is a primer for doctoral students in the early phases of working on their dissertation. It sets out to provide some basic guidelines for how to overcome the significant challenge posed by publication requirements. It commences with an auto-ethnographic narrative of the doctoral process. It proceeds to address the differences between the monograph and the article-based thesis, highlighting the pros and cons of each. This is followed by some general advice on how to publish from your $\mathrm{PhD}$. In conclusion it deals with the issue of an academic identity and the emotions involved in the process of development.

\section{THREE YEARS AND 100000 WORDS}

I started my $\mathrm{PhD}$ in 2007 in a UK university and completed it in 2010. Three years of total immersion in the field, of total involvement and engagement with my data, analysing, theorising and summarizing, watching and waiting for themes and findings to emerge from this complex combination of theory and practice; zooming in and zooming out of the field and building my research skills, writing skills and the sense of myself as an 'academic'. My PhD thesis was in the form of a monograph, the more common form of $\mathrm{PhD}$ in the UK. In fact, I was not aware of the option of completing a PhD through publication until very far into my $\mathrm{PhD}$. However, I am glad that I pursued my $\mathrm{PhD}$ in the monograph form as I believe it has helped me to hone my writing skills; forcing me to construct a narrative (or golden thread) that would develop over 
100000 words and allowing me to 'wallow' in the literature, data production, analysis and most importantly of all, helping me to develop academic writing skills, with a view to perhaps writing a book at some point in the future (although, as it stands books are not necessarily well regarded as academic outputs - particularly in the UK - something that I find very confusing as I would consider this the ultimate achievement and would aspire to eventually write a book).

I must admit to being slightly naive in writing my $\mathrm{PhD}$ - initially seeing it as an end, rather than a means to an end. It was not until I was into my final year that I realized that, on its own, my monograph was considered a mere exercise, an 'amuse bouche' before the real academic work that would establish my reputation began; this real work being the process of pulling out findings and ideas from my monograph for journal articles. This was not something that I had really considered and the level of competition and expectation came as somewhat of a shock. Was the fact that I had crafted 100000 words with a narrative flow that told the 'story' of my research journey and contributed new knowledge in my subject area (Gender and Entrepreneurship Education) not enough? Well, no it wasn't. The PhD thesis is merely a calling card, a way of being in the frame. It is the resulting journal articles that will get you through the door so that you can actually share and 'sell' your ideas and contribution to knowledge. So how can this be done?

The challenge of developing 7-8000 word articles from a prospective choice of 100000 words is immense and should not be understated. How could I provide the context, the richness of detail and the sense of beginning, middle and end, a sense of 'completeness' that is vital to a successful monograph? How would I do justice to my data, give voice to my research respondents and summarize the many findings and theoretical contributions that a monograph inevitably contains?

Well, one activity, which I had thankfully started before completing my $\mathrm{PhD}$, really helped with this and that was presenting papers at conferences. This was a good training ground - forcing me to take a different view on my research and its presentation, making me focus on specific aspects or emerging themes rather than trying to encapsulate the whole thesis in one presentation. This also allowed me to get feedback on my ideas and to get a sense of the areas that were worthy of further development and presentation. This was not an easy process - I presented my first working paper at the International Small Business and Entrepreneurship (ISBE) conference, just a few months after I had started my $\mathrm{PhD}$. To present the very early stages of my ideas to my peers, many of whom I had read and cited, was terrifying but ultimately rewarding. The odd nod of agreement, the suggested extra reading and introductions to 
others studying and researching in my field were invaluable and, I believe, laid the foundations for developing later, more confident pieces of writing and ultimately to my first paper being published in a well-respected journal in 2012.

Again, the process leading up to getting the journal paper published was not just about me working in splendid isolation, sweating to craft a paper that would encapsulate my research. It was partly about that but it was also about my growing involvement in a community of practice and participating in the wider academic community that I felt wanted to hear what I had to say. This confidence and involvement has been strengthened by presenting papers and work in progress from 2007 to the present, by having conversations with my peers and also by becoming involved in the publishing process by proxy. By this I mean that, towards the end of my $\mathrm{PhD}$, I volunteered to review for a journal in my field. This was a very big step for me and I would not have done this had I not been encouraged by those 'Nellies' in my academic community who suggested I 'just get in touch with the editor'.

I now review for several journals and this has provided invaluable insights into what makes a 'good' journal paper. It has emphasized a certain 'form' of readable and engaging paper and has also taught me about the use of language in academic writing. That the main point is to be clear, to have clarity in both the words and structure that you use. Initially, I would have thought that the use of long words and 'academicese' would have proved that I was a 'proper' academic writing in a proper academic style. However, once I started to review, it was clear that those authors who use plain, 'unflowery' language inevitably get their message and arguments across better. Also, the signposting used in a paper is very important. The headings used sparingly, to guide the reader through the text, the logical unfolding of the argument. The more papers I reviewed, the more 'obvious' the merits of this approach became.

And yet, I still had 100000 words to 'chop' or 'slice' up into articles in order to do my three years of intensive research and writing. It was all very well having an understanding of the form and content of a good journal article but how could I write one without watering down my findings or losing sight of the bigger, more complex, picture?

I started by considering my findings/discussion chapter - this, after all, is my contribution to theory and to my field. These are the ideas and theoretical extensions that will supposedly help to move my particular field on. These are the ideas that I needed to tell others about - but what were they and how could I summarize them?

Throughout my $\mathrm{PhD}$, certain words, phrases or ideas started to emerge and these were threaded through my discussion and findings. Phrases 
such as 'the suspension of disbelief', 'the fictive entrepreneur and student', 'the gendering of discursive space', for example, permeated my attempts to make sense of my data and of my findings. There were also themes linked to the staff and students that I had interviewed and observed. Staff attitudes to entrepreneurship education as a 'fad', female students unanimously labelling themselves 'business owners' rather than entrepreneurs. Here were emergent themes that might help my peers and fellow enterprise educators make sense of what is 'going on' in the classroom and curriculum.

Starting with these ideas or findings first, forced me to really think about the focus of each paper (and I include conference papers here as preambles to journal papers). They helped me to identify the literature to draw upon in situating their importance and contribution to knowledge. Obviously, I could not include all of my literature review in a journal paper, but by focusing on one element of my findings I could draw on the literature that highlighted and explored individual, relevant themes. I could also do a more focused review of any new literature published since I completed my $\mathrm{PhD}$. I did not have to read everything - just to identify new developments in my field that linked to the particular finding or theme that each paper explores. I very often use the theme or idea in the paper title too - to add focus and to make it clear exactly what the paper is 'about'. This also acts as an anchor for me and (hopefully) stops me from drifting away from the main focus of the paper.

There are some who suggest that there is a tendency to slice research too thinly when developing papers from a monograph. However, although my papers are obviously based upon my thesis, much of what I now write is actually a synthesis of those findings, further engagement with newer literature and also, as I work in the area that I research in, on-going ideas, questions and issues that are constantly emerging from my practice as a gender-aware and critical entrepreneurship educator. Therefore, I do not see the papers from my $\mathrm{PhD}$ as being 'sliced' out of my $\mathrm{PhD}$. If anything, they are part of a bigger research 'sandwich', a 'filling', which is surrounded with more up-to-date research and my own continuing engagement with and understanding of the theoretical and practical issues highlighted by my $\mathrm{PhD}$.

That said, to date I have only had one journal paper published (although I am currently working on five). It was a positive process (in hindsight, of course). The first set of feedback from the three reviewers suggested that, although I did have something interesting to say, I was not articulating it clearly and concisely. All three reviewers suggested major revisions in different areas, which, at first, almost paralysed me, as my first thought was 'This is an impossible task!'. However, after a week 
away from both my paper and the feedback, I was able to see the points that the reviewers were making and really appreciated that, although some of the feedback was blunt, it was constructive. It was well-meaning and ultimately, it strengthened my paper and made it much better. The comments introduced me to new theories and concepts that I now draw upon in my developing writing and research, so I am grateful for the time and care that these reviewers gave to my work. Having responded to the feedback, the next set of reviews (from two reviewers this time) still asked for minor revisions. This was actually a relief as I was unsure whether I had addressed the major issues from the previous reviews. Again, the minor revisions improved the paper and it was eventually accepted for publication in the International Small Business Journal (ISBJ).

Although it felt like a great achievement, I could not rest on my laurels and relax. I soon realized that getting this journal paper published was not the end of anything but the start - just as getting my $\mathrm{PhD}$ was not really the end of anything, it was more about gaining entry into an academic community where I would then have to articulate the ideas, themes and importance inherent in three years work and 100000 words. However, publishing an article in a high-quality journal does give a sense of personal and academic progression and growth. It is a form of acceptance into an academic community of practice and feedback from your peers that you are included in their conversations and that you have something to say.

This was a single-authored piece and I have only recently started to write with others. This may be a drawback of the single authored monograph, as it does not allow you up to writing collaboratively. I think it also made me less happy to share my embryonic ideas with others as I was very heavily invested in the work - it felt like any criticism of my $\mathrm{PhD}$ and my ideas was ultimately a criticism of me. I also worried that working with others would potentially hold me back as I would have to wait for others to complete work, or that other people would let me down. You do become very self-reliant when writing a monograph and this is a hard habit to break.

But, I am now writing with others and, far from being the onerous, negative experience that I had envisaged, it has proved to be liberating, creative and intellectually stimulating. I am currently working on several papers with co-authors ranging from one other to four others and it really has been a learning experience. The ideas and insights that more than one person can generate have helped me to improve both my approach to wringing and also my understandings of other bodies of knowledge such 
as philosophy and history - which can only make my future research foci and questions richer and more engaging.

Although there are some drawbacks of the monograph, I realize that it was a rare luxury and I am truly grateful to have spent three years immersed in a field of study and in research that I find fascinating but also believe is crucial for the development of teaching and learning in my field. Writing journal papers allows me to engage in conversations with my peers about my research, it allows the spotlight to focus on areas, which may provide others insights into their own practices in this area and it ultimately allows me to signpost others to the 'bigger picture' of my doctoral thesis (for those who are interested) but also to be very clear about why, what I have spent three years and 100000 words exploring, is important. I would hope that that is what all researchers would wish for; to feel that your hard work, energy and passion has had an impact, has made a difference and has ultimately been worth it $P$

At first glance, describing the $\mathrm{PhD}$ as a period of apprenticeship seems rather appropriate. Indeed, Lave and Wenger (1991) articulate the idea of legitimate peripheral participation and how it helps people who are learning a trade or learning the practices of a particular community to move from novice to expert community practitioner through a process of situated learning; a form of apprenticeship.

Had I chosen to pursue a formal, trade-based apprenticeship I would need to learn from those who had already 'mastered' the trade or profession because, in order to learn how a community of practice works we need to learn from those people who are already experts and already know how things work. Thus we need to sit with 'Nelly', ${ }^{1}$ who works the important machines - the woman who has been part of the company for 20 years, who has seen the company develop and watched others come and go. Nelly knows how everything works and who everyone is. Watch her, observe how she moves, the things she says, take it all in, revel in her 'Nellyness' and aim to go from just sitting with Nelly to being like her. This metaphor illustrates the notion of moving from peripheral participation - from 'lurking', listening to conversations but not being involved in them, reading academic papers and watching presentations. It also helps to articulate the notion of the $\mathrm{PhD}$ as an apprenticeship, where you learn the tools of the trade and that a $\mathrm{PhD}$ validates you as a member of this community of practice. As such it also mimics a traditional apprenticeship - however, there are numerous differences between a traditional apprenticeship and the academic one. In the traditional apprenticeship, the apprentice starts with the most peripheral assignments, which provides a position from which s/he can watch, which tools are used for which assignments, and thus slowly builds an idea of the 
structuration and meaning of the community of practice. The apprentice advances from observing to participating in increasingly more difficult assignments until s/he becomes fully skilled. Thus, through participation the apprentice advances from being a novice to becoming more and more expert. (Neergaard et al., 2012) and learns the 'habits, norms and practices' of their academic community (Golde, 2010, p. 81).

In the academic apprenticeship, there is rarely a period of pure observation. Usually, in Europe, the doctoral student is thrown in at the deep end, although this may be different in North America, where they may be more structured and include coursework and examinations throughout the period of study (Coimbra Group, 2012). Further, although doctoral students work under supervision, often they conduct the practical part of their research on their own, gathering data because the doctoral work has to be independent; it cannot be carried out as a collaborative effort, as then the doctoral student cannot claim it as his or her own. This also means that as described above, the 'real work' does not begin until the $\mathrm{PhD}$ is completed. However, as the article-based thesis is gaining popularity over the monograph owing to the publish-or-perish mantra, this practice is also changing, particularly in those areas that suffer from what could be termed 'natural science envy'.

In some countries, therefore, the doctoral process is becoming more and more structured and school-like, with doctoral students having to follow standardized courses rather than carrying out the scientific practice under expert supervision, thus moving from participatory learning towards more behaviouristic practices. One could also say that the monograph-based thesis can be associated with Lave and Wenger's (1991) communities of practice ideas, whereas the article-based thesis plays the numbers game. So how do you choose which road to travel?

\section{MONOGRAPH- OR ARTICLE-BASED THESIS?}

There are two types of theses that you can choose to write, independent of the research strategy chosen: the monograph- and the article-based thesis. The former was predominant in many countries throughout the twentieth century, and in some countries, such as the UK and Australia, it still is. In most other west-European countries the article-based thesis is, however, gaining popularity.

The tradition of the monograph-based thesis is closely connected to two issues: (1) the tradition within the field and (2) the period of time a doctoral student has to complete the thesis. In general, there is strong tradition for the monograph in qualitative research and, for example, 
within the humanities. In the past, in some countries, such as Sweden, a doctoral student could spend up to eight years undertaking research before submitting. In Denmark a similar tradition ruled, until the end of the twentieth century when new legislation was invoked. So it used to be a quite lengthy process and advancement in universities was based on factors other than purely publication. However, because of the intensified pressure for publication in the social sciences owing to increasing globalization and mobility of researchers, the monograph-based thesis is today rapidly being phased out. This is an area of debate in the UK, where it is suggested that the nature of the doctorate is changing, with consideration of the $\mathrm{PhD}$ as 'process' or the $\mathrm{PhD}$ as 'product' (Park, 2005). In this scenario, the monograph-based doctorate is positioned as focusing on the process of writing, researching and developing a major piece of academic writing, whereas the articles-based doctorate is positioned as focusing on the 'product' of the research; being aimed at producing articles that are published in highly regarded journals.

While both forms of PhD have aspects of an apprenticeship, given that they both require candidates to learn the language, mores and 'rules of the game' regarding publishing in their particular field, the monograph has the potential to lengthen this apprenticeship. Indeed, in the $\mathrm{PhD}$ as process versus product debate highlights issues around the academic credibility and expectations of those writing a monograph and those actively pursuing a $\mathrm{PhD}$ through publication. Ballard (1996, pp. 13-14) points out that $\mathrm{PhD}$ candidates are still apprentices in the profession of research in their discipline; and so their theses are judged in terms of current competence and future promise as academic colleagues'. Consequently, you would assume that this would mean both types of doctoral thesis are viewed as equal. However, given the onus on writing rather than publishing this may mean that monographs are not considered to be the 'finished' piece of work or product and their authors may not be seen as having academic credibility, given the need for them to prove this potential by then publishing high-quality articles that evidence their promise as academics. Arguably, those who have completed an articlebased doctorate will have already 'proved' their academic worth to the wider community of practice by virtue of already having published journal papers.

Depending on the choice of methodology for the thesis, the research process of each of these two types may be vastly different. However, there are also many similarities. In the following, an overview of each of these approaches is provided. See also Table 8.1. 
JOBNAME: Fayolle \& Wright PAGE: 9 SESS: 4 OUTPUT: Tue Sep 24 08:30:12 2013

\section{Table 8.1 Some characteristics/issues related to monograph-based and} article-based theses

\begin{tabular}{|c|c|c|}
\hline & Monograph-based thesis & Article-based thesis \\
\hline Authorship & Single & Single and multiple \\
\hline Coherence & $\begin{array}{l}\text { Strong emphasis on a holistic, } \\
\text { narrative arc through the whole } \\
\text { thesis }\end{array}$ & $\begin{array}{l}\text { Smaller articles may lead to a } \\
\text { sense of disjointedness and less } \\
\text { scope to develop strong } \\
\text { arguments. }\end{array}$ \\
\hline \multirow[t]{7}{*}{ Publications } & $\begin{array}{l}\text { Provides the opportunity to work } \\
\text { in-depth and independently }\end{array}$ & $\begin{array}{l}\text { Provides opportunities to write } \\
\text { with more experienced authors }\end{array}$ \\
\hline & $\begin{array}{l}\text { The thesis in its entirety may need to } \\
\text { be complete before publication of } \\
\text { findings }\end{array}$ & $\begin{array}{l}\text { Potential for quicker publication } \\
\text { of findings prior to completing the } \\
\text { thesis }\end{array}$ \\
\hline & $\begin{array}{l}\text { Opportunity to develop and explore } \\
\text { more major findings due to the } \\
\text { length and scope of the thesis, with } \\
\text { the potential for developing more } \\
\text { papers than an article-based thesis. }\end{array}$ & $\begin{array}{l}\text { Potential for asking more limited } \\
\text { research questions and developing } \\
\text { fewer major findings due to } \\
\text { limitations of the article format }\end{array}$ \\
\hline & $\begin{array}{l}\text { Greater potential to publish thesis as } \\
\text { a book. This may, however, distract } \\
\text { from writing journal articles }\end{array}$ & $\begin{array}{l}\text { Author can become more } \\
\text { experienced, more quickly in the } \\
\text { art of writing journal articles }\end{array}$ \\
\hline & $\begin{array}{l}\text { It may take longer for the author to } \\
\text { create journal articles given that } \\
\text { they will have to heavily revise their } \\
\text { work to suit a journal article format }\end{array}$ & $\begin{array}{l}\text { Earlier publication can result in } \\
\text { gaining advice from experts in the } \\
\text { field and gaining earlier entry into } \\
\text { the academic community }\end{array}$ \\
\hline & $\begin{array}{l}\text { Author may feel they are working in } \\
\text { isolation and receive little feedback } \\
\text { from the wider academic } \\
\text { community about their research. } \\
\text { This may prove demotivating and } \\
\text { the field could potentially 'move on' } \\
\text { during the course of writing the } \\
\text { thesis }\end{array}$ & $\begin{array}{l}\text { Potential to receive encouraging } \\
\text { and insightful feedback from } \\
\text { experts that can provide positive } \\
\text { reinforcement }\end{array}$ \\
\hline & More emphasis on $\mathrm{PhD}$ as process & More emphasis as $\mathrm{PhD}$ as product \\
\hline \multirow[t]{2}{*}{ General } & $\begin{array}{l}\text { Encourages authors to spend a lot of } \\
\text { time planning, reading and } \\
\text { developing the structure of the } \\
\text { thesis before committing to writing }\end{array}$ & $\begin{array}{l}\text { Encourages author to start writing } \\
\text { straight away }\end{array}$ \\
\hline & $\begin{array}{l}\text { Completing such a large piece of } \\
\text { writing may feel overwhelming and } \\
\text { demotivating }\end{array}$ & $\begin{array}{l}\text { May make the process more } \\
\text { manageable by dividing the work } \\
\text { into more manageable, time } \\
\text { limited parts }\end{array}$ \\
\hline
\end{tabular}




\begin{tabular}{ll}
\hline Monograph-based thesis & Article-based thesis \\
\hline $\begin{array}{l}\text { A danger that if the author } \\
\text { withdraws from the PhD they will } \\
\text { have nothing to show for their time } \\
\text { and efforts }\end{array}$ & $\begin{array}{l}\text { If the author has to withdraw from } \\
\text { the PhD for any reason, at least } \\
\text { they have not 'lost' everything and } \\
\text { will have had some articles } \\
\text { published }\end{array}$ \\
\hline
\end{tabular}

\section{The Monograph-based Thesis}

The main purpose of the monograph is to present primary research and original scholarship within a limited area of knowledge (Thompson, 2002). In former times, it was regarded as vital for academic career progression; today, it has lost its standing in many of the social science disciplines, with some suggesting that it can result in overspecialization and can disadvantage students who spend so much time immersed in researching and writing their monograph that they 'do not graduate from doctoral programs as skilled teachers, adept at engaging classes of various sizes and different mixes of students and versed in scholarship on student literacies and learning environments' (Smith, 2010, n.p.). The monograph is single-authored, a characteristic which distinguishes it from the article-based thesis in which one or more articles can be co-authored. The monograph seems to be becoming less popular as the impact of theses as information sources has been generally declining over the twentieth century and that journal articles are cited far more than monographs (Larivière, et al, n.d.), and this is an argument for pursuing an article-based thesis but also it also places importance on those who do pursue a monograph-based thesis to actually publish from it.

However, if we view the monograph-based thesis from a process perspective rather than a product perspective, it is not often in a research career that there is an opportunity to immerse oneself so completely for a lengthy period of time, in the way that is necessary in order to produce a monograph. Actually, the only time in a research career that this is expected is during the doctoral candidacy. However, critics of the monograph, mainly publishers and advocates of open source, perceive the monograph as an outlet for excessive specialization appealing only to small audiences. ${ }^{2}$ Douglas Armato and others believe that the monograph has to find another form of outlet than the printed version, because of high publishing costs and cuts in library budgets, which means that access to monographs is likely to be even more limited in the future. The following example highlights this development, since the sales of monographs to libraries have decreased tenfold, from 2000 to 200 since $1980 .{ }^{3}$ 
For doctoral students, there are other considerations too. First, even if you have a supervisor to guide your work, you are more or less on your own in writing the monograph. There is no co-authorship to ease you into the academic writing tradition of your chosen area, nor anybody with whom to share the burden of writing. However, neither is there any question that this is your work and nobody else's. Further, the writing process itself may be less fragmented and therefore more easily managed, and after the $\mathrm{PhD}$ is over you actually have the satisfaction of holding a book in your hand. There are challenges, however. These include getting your $\mathrm{PhD}$ condensed into articles either concurrently or afterwards. Having worked so long with your topic means that you have been totally immersed and this may be either positive or negative: positive because you have had more time to reflect, so it may become a better publication, negative because you have been totally immersed and therefore may have difficulty in seeing the various avenues available. Sometimes, when you have worked for so long on putting something together, it is difficult to grasp just exactly how it can be cut into smaller pieces. Publishing from a monograph can also seem more difficult because it can be a challenge to separate out the various insights gained and identify those that will form good points for individual articles. It may be helpful, while you are writing up the findings, that you ask yourself: 'What are the three, four or five major points of interest in my thesis. Where are the wow-factors?' Once you have pinpointed these you can start constructing papers around them.

A final challenge is that once you have written a monograph, submitted and defended it, you may feel that you do not want to revisit the topic again for some time. Three years or more is a long time to spend researching the same topic. Nevertheless, this is the time when you have to start converting your dissertation into articles. There are also concerns about whether doctoral candidates are apprenticed 'with' or apprenticed 'to' and supervisors take ownership of the work of those doctoral students they supervise (Walker et al., 2008) or provide the only scholarly input or advice; his is a danger of the monograph, namely its 'highly individualistic' research and supervision structure (Pearson, 1996). This would seem to make it all the more important, when pursuing a monograph-based doctorate, to network, attend and present at conferences and seek feedback and advice outside your particular supervisory team.

\section{The Article-based Thesis}

As the title illustrates, the article-based thesis usually consists of a collection of articles. However, there are differences in the demand of individual universities with respect to: the number articles required to 
constitute the $\mathrm{PhD}$; whether these have to have been published by the time the thesis is submitted; and the 'wrapping' required. There are probably as many approaches as there are universities, thus no uniform formula can be provided. However, in the present competitive environment, the article-based thesis is rapidly becoming predominant. Proponents of the monograph may argue that this detracts from the potential depth of insight that can be gained from research, and this may be true if the articles are allowed to become 'islands in the stream' with little connection between the findings presented in each. Nevertheless, strategically speaking, it is possible to undertake precisely the same research in precisely the same way as one would for a monograph, only separating the chapters as individual articles. For example, most doctoral studies involve doing a thorough literature review in order to gain knowledge of what came before, since research does not exist in a vacuum. The challenge here is that literature reviews are notoriously difficult to publish, so it is necessary to make sure that its relevance is argued and positioned well with respect to existing reviews and theoretical relevance. Further, all research needs to include a methodology section and it is possible to make a methodological contribution to research, so that your methodology section can actually also become an article. However, it is quite rare. Thus, it is mainly in the presentation of the findings that the doctoral student needs to pay attention.

The publications in an article-based dissertation may also contain joint publications, if the author's independent contribution can be clearly indicated. These publications typically include three to five international refereed articles, and they must have been published earlier or been accepted for publication before the doctoral dissertation is sent for pre-examination. The division of responsibilities and credit in joint publications must be clarified at as early a stage as possible, or at the latest when an article is published. Some universities require the doctoral student to be first author on all articles submitted for evaluation, so it is important to work out how to deal with these practicalities.

\section{SOME GENERAL ADVICE ON DEVELOPING PAPERS FOR OR FROM YOUR PHD}

The number of papers that you can develop from your $\mathrm{PhD}$ finally depends on the number of major findings. Usually, there will be between three and five of these - as well as numerous minor findings, but these are generally by-products and difficult to develop whole papers around. However, as you are writing up or rewriting the major findings, you may 
discover that they give rise to new angles. If you have authored a monograph, you can choose to turn these into articles, book chapters, or even a book. Some publishers, for example Edward Elgar, will publish an adapted copy of your thesis as a book if they think that the topic has a sufficiently broad appeal and the findings are interesting and novel. Book chapters may be relevant alternatives for, for example, literature reviews, which cannot find a journal outlet, or for publishing methodological material. With regard to articles, there are a number of challenges, which you can encounter. These include (1) choosing a target journal, (2) dealing with being a non-native English writer, and (3) understanding and dealing with rejection.

\section{Choosing a Target Journal}

Experts tend to disagree on this issue, but most advocate that you choose a target journal before you start to write. The advantage is that you can set up the manuscript according to the journal rules right from the start. This is particularly important if the submission rules are highly regulated, such as for the American Psychologist Association (APA). Failing to comply with the rules - and it could be a very minor issue - could result in a desk reject.

However, the choice of target journal is very dependent on what is the key research topic or theme in your paper and what type of article you wish to write. Choose a journal that speaks your 'language', and that will accept your methodology and your theoretical standpoint. Also, scrutinize your list of references and identify the journals from which you mainly source your material. Then it is likely that these represent the conversation that you want to join. As a doctoral student it is unlikely that you will be published in highly ranked journals (A, A+) unless you are writing together with someone who is used to publishing in these journals. If you do, take advantage of it and learn from that experience, but remember it is really difficult to be accepted and most journals have very high rejection rates, as discussed elsewhere in this book (see, for example, Chapters 1-3). So there is a time-related trade-off between 'Do you want to be published' or 'Do you want to be published in highly ranked journals?' The review process is often lengthy, so there is a question of whether you can wait and getting published in a highly ranked journal may well take a lot longer. Even if you get past desk reject, reviewers may still reject your paper, so you really also need to have a plan $\mathrm{B}$.

It is not always a case of simply submitting to a different journal exactly the same paper that was rejected. Often, if one decides to send a 
rejected paper to a different journal there is work to be done on re-crafting the paper to reflect the concerns and conversations of this newly identified journal. This may involve an analysis of the papers in the journal that are engaging with your research focus, reading papers from the journal and citing them in your previously rejected paper. As a reviewer it is sometimes clear that a paper was originally written and submitted to a different journal (and rejected) due to the emphasis on certain citations and conversations, and this indicates to reviewers that the author is not necessarily interested in the aims and concerns of their particular journal but only in getting their paper published - anywhere, regardless of the journal's readership or research focus. This does not often work to the paper's advantage and can result in another rejection. Needless to say, you should not submit your paper to more than one journal at a time as this is considered bad practice and, as reviewers tend to be specialists who review in their specialist area for many different journals, this may be exposed. Similarly it is likely that simply sending exactly the same rejected paper to a different journal would result in it being sent to the same reviewer who originally rejected it. Both of these practices can lead to further rejection and also often annoys reviewers.

Finally, regardless of the journal that you eventually identify, you have to write a persuasive covering letter to the editor, arguing why they should publish your paper. You may find yourself in the position that you want to introduce a new discussion in a journal. In this case, you need to explain what the novelty of your paper is, and why it would be advantageous for that particular journal to start a new thread of discussion. However, the cover letter has to be written with humbleness, thus, writing that you believe your paper to be excellent, is not a persuasive argument - that is why we have peer review, we let other people decide what is excellent. Arguing that you believe that the paper contributes in $\mathrm{x}$, $\mathrm{y}$ and $\mathrm{z}$ ways to advance our knowledge would most certainly work better. It does not guarantee that your paper will be published because it still has to go through the review process, but it may get you over the first hurdle - that of desk reject.

\section{Dealing with Being a Non-native English Writer}

There is pressure on all doctoral students and early career researchers to publish in highly ranked journals and these are likely to be those published in English. Therefore, it is important that non-native English writers publish in English in order to secure academic employment and tenure. However, many students will not have received any formal 
writing training during their doctoral studies and this can lead to issues around writing style which can impact on an article's chances of being published.

It is important that authors take care that they do not play the role of the tailors in the tale of 'The emperor's new clothes', dressing up the paper in elaborate and non-transparent language. As noted at the beginning of this chapter, those authors who use plain and 'unflowery' (down to earth) language invariably get their message and arguments better across. Using unusual words can be interpreted negatively as either trying to show your superiority or hiding your insecurity. Thus, you should ensure you use appropriate language. Whether you are a native writer or not, proofread to ensure that (typing) errors do not detract from your message - there is a big difference in writing 'casual' instead of 'causal'.

One approach would be to write your article in your native language and then have it translated into English - however, this may make it more difficult (and more time-consuming) to respond to advice on revisions if the paper goes to review. Also, if the paper is not translated by someone who has knowledge of your particular field or research tradition, this may result in discrepancies and mistakes which can undermine the academic credibility of your paper. Thus, if you are not a native English writer, it is advisable to write the paper in English from the beginning and get it reviewed by a certified language auditor. If this is not possible then you should at least ask a native English speaker to read your article before it is submitted.

It has been suggested that it is more difficult for non-native English writers to be published in the social sciences than it is for those writing in the field of science or engineering because 'science and engineering articles have a fixed set of rules and writing such articles is nothing more than a mechanical process' (Basaran, 2009 p. 375-6). However, while this may be a common perception, Wright's chapter in this book highlights that there are several accepted 'rules' and approaches to the construction of an entrepreneurship paper that are also recognized as important for the social sciences generally. Such 'rules' and commonly accepted (and expected) approaches to writing for English-language journals can also be learned through engaging with the academic community in your particular country who have faced similar publishing challenges and have succeeded in publishing in high-quality Englishlanguage journals. Early iterations of your work can also be 'tested' for the clarity and accessibility of the language by presenting at international conferences conducted in English.

That said, most reviewers do appreciate the pressure that non-native English authors are under to publish in English-language journals and a 
paper that has obviously been written by an author whose first language is not English will not necessarily result in the paper being rejected. Often reviewers will recognize the author as a non-native English speaker and offer advice on how the paper can be improved so that it is clearer. However, this will usually only happen if the initial idea or focus of the article is considered to be of interest and relevant to the particular journal. A paper that has many discrepancies and makes clumsy use of the English language may be considered beyond repair and be rejected.

For these reasons, publishing an article in a highly ranked journal as a non-native English speaker may seem like an overwhelming task but fortunately there are many useful resources which can support you. Second language writing is an increasingly researched topic, it even has its own journal (Journal of Second Language Writing ${ }^{4}$ ) and several authors have published useful articles and books on this subject (see, for example, Belcher, 2007; Burgess and Martín-Martín, 2008; Cho, 2004; Delamont, 2011; Wallwork, 2011).).

\section{Understanding and Dealing with Rejection}

Experienced academics can talk about rejection of journal papers in a very understated and blasé way that seems to ignore the emotional impacts of submitting your research to journals. In attempting to get your research published, particularly when submitting to high-quality journals that have a very high rejection rate (such as those outlined Fayolle's introduction to this book), you are attempting to push the door open to your academic community. Sometimes the door will nudge open a little and you will get a glimpse of what it is like to publish a paper (perhaps if your paper gets to the revise and re-submit stage but is then rejected) and sometimes the door will be resolutely slammed in your face (with a desk reject). However this rejection happens, it will feel like not only a rejection of your ideas but also a rejection of you as a person. For these reasons it is recognized that "publishing takes an emotional toll on researchers' (Day, 2011, p. 704)

Perhaps one way of dealing with rejection is to see your paper through the eyes of the editor of that particular journal. Does this paper make a clear contribution to the conversations in the journal and to the knowledge in the field more widely; given the demands of the lack of physical space (that is, pages) to publish in traditional journals, the costs of publishing and the time taken up with the review process, papers that do not immediately make it clear how they meet these criteria are likely to be rejected without going to review. Editors are under great pressure to 
meet the demands of their editorial boards, their reviewers, their readership and the authors who submit papers. Does your paper really help them to meet these demands by making your contribution to the journal and the field explicit from the very start?

Then there is the issue of the paper being rejected by one reviewer but being suggested as needing major revisions by another, or general disagreement by the reviewers about the weaknesses or strengths of your paper. Again, the reviewers are under intense pressure to complete their review in a timely and constructive manner and, although the editor may consider the subject matter worthy of further exploration, ultimately if you have not made your contribution clear it is likely to be rejected at review stage. Also, reviewers may have different approaches to your particular area or they may be experts in one discrete aspect of your research (such as the industry sector or the research methods employed). Therefore, different reviewers are likely to have different 'takes' on the value and credibility of your research given their own disciplinary (and sometimes interdisciplinary) understandings. There has been no concerted research into this area by scholars in the field of Entrepreneurship and indeed it is a subject that is rarely addressed. However, some scholars in fields such as psychology and management have considered the reasons for and impacts of journal paper rejection.

For example, Fiske and Fogg's (1990) paper offers insights into this process when they write:

criticism can be serious in several diverse ways. A critical flaw in the design may (in the eyes of the reviewer) make the paper worthless. An omission or ambiguity in exposition may make the reviewer uncertain about the soundness of the research plan. Departing from current practice in a research area may cause the reviewer to infer that the author is not sufficiently qualified in background and experience to attempt such a research study. (p. 592)

They go on to suggest that, in their field of psychology, the most serious criticisms relate to the author's interpretation of the research findings and the conclusions drawn, with the next most serious criticisms linked to the presentation of the conceptual work that was done before the empirical research was started. This links to both the quality of the literature review and the identification of and engagement with an appropriate theoretical basis for the research. Finally there were criticisms in areas that most authors would expect - the results, methodology and research design. Ultimately, Fiske and Fogg (1990, p. 593) suggest that two-thirds of critical comments were linked to presentation issues -that is, the 'exposition and description' of the research, rather than the actual research 
activities themselves. Other, more minor, criticisms revolved around poor spelling and grammar, issues that are easily preventable through thorough proofreading and/or having the paper read by critical colleagues before submission to a journal. Rereading or proofreading a manuscript that one has worked on for many weeks or months can be very painful but it really is a necessary and straightforward way of setting up your paper for at least being put out for review.

More recent research in the field of management (Day, 2011) recognizes that negative responses to rejection are common and to be expected. They are part and parcel of the day-to-day development and progression of academics professionals. Furthermore, even if a paper is ultimately rejected there are sometimes glimmers of hope to be taken away from the experience. You will most likely be given some insights into how your paper could be improved to make it suitable for publication (even if that is not in the journal it was rejected from). It is important to take note of the reviewers' comments and advice to help you to develop the paper, especially if you have submitted to a highly ranked journal. This is $\mathrm{A}^{*}$ quality feedback from an expert in the field who has actually read and engaged with your research, and it is not often that you receive that!

When authors receive positive encouragement but are asked to revise and re-submit they sometimes do not do this, as rewriting can also be a process tinged with negativity - particularly if you feel that the paper will be significantly 'different' from the one you originally conceived. This is understandable but self-defeating, given all the issues discussed above and the fact that a 'revise and re-submit' moves you one stage further along the road towards being published. For those who have written a monograph this is even more important, given that very few people will actually read your research in monograph format and publishing articles is increasingly becoming the main way of disseminating and sharing your work and building your academic profile.

Ultimately, whether you respond in a negative or more positive way to having a paper rejected, you should recognize this as part of the learning experience in the move from academic novice to expert and take heart from the fact that it happens to all scholars and our negative reactions are normal and to be expected (Day, 2011). Indeed, there are eminent professors, who owing to the anonymous peer review process, still have papers rejected. The fact that they are eminent professors is testament to their ability to deal with rejection in a way that has not stopped them from continuing to strive to be published despite this. This also suggests that the more rejections we experience, the better able we will be to deal with them in an increasingly constructive way. We should not seek to never have a paper rejected (as this would be impossible or mean we are 
aiming too high) but should instead seek to manage our responses to having papers rejected and accept this as part of the process of academic development and this is something that potentially never ends as our field is constantly evolving and new ideas are constantly being tested, explored and developed.

\section{MOVING FROM THE PERIPHERY TO THE INNER CIRCLE: A QUESTION OF IDENTITY?}

In developing beyond writing your thesis, you will move from being a novice academic to one with more understanding and credibility within your own research community, but this can bring its own issues for doctoral students and early career academics. Becher and Trowler (2001) remind us that 'Being a member of a disciplinary community involves a sense of identity and personal commitment, a "way of being in the world", a matter of taking on "a cultural frame that defines a great part of one's life" (2001, p. 47, quoting Geertz). This sense of identity as an academic develops over time through the socialization involved in spending three (or more) years developing and writing a monograph (or articles for publication). With this comes a sense of confidence, of finding your own voice and realization that you have something to say that is interesting, tells your community something new and helps to move knowledge in your field on.

However, this sense of cultural and disciplinary identity can be complicated for those trying to publish in the field of entrepreneurship as it is often positioned as interdisciplinary (indeed, there are suggestions that it has to be interdisciplinary, given the breadth of inquiry and theoretical engagement that it encompasses). Some may draw upon the fields of economics, management or organizational behaviour or like the doctoral thesis illustrated in the opening of this chapter, upon sociology, education and gender theory. However, this interdisciplinarity also greatly increases the potential audience for your publications and this can only be a positive thing. Non-native English speakers will also have to deal with the issue of establishing themselves as academics in two different languages. Issues around rejection and lessons learned can be seen as a form of identity threat on the road to establishing ourselves as 'experts' or at least capable of meeting the standards set by our academic community. It is acknowledged that this can have different effects on those students positioned as different to the 'traditionally' white, middleclass, male academic (Ivanic, 1998). This is also an issue when academic success is linked to particular outcomes, such as publishing, with the 
result that "many younger academics ... must negotiate on a daily basis not only their attempts at "becoming" but also the threat of "unbecoming", (Archer, 2008, p. 385).

So, ultimately, what does being an expert mean? Golde (2010, p. 83) sums this up when he says: 'Experts are able to ask important questions, to competently conduct research, to assess others' work, to understand the important ideas in their field, to communicate what they know and to apply their knowledge and understanding to solve important problems.' This would also seem to be a succinct description of the characteristics we need to emphasize in writing journal articles so they are considered important and interesting enough to be published in the high-quality journals that a successful academic career is built on.

\section{NOTES}

1. On-the job training (OJT).

2. www.upress.umn.edu/about-us/history-and-fact-sheet-folder/what-was-a-universitypress-1/iii.-the-monograph

3. www.researchinformation.info/news/news_story.php?news_id=1051.

4. www.journals.elsevier.com/journal-of-second-language-writing/.

\section{REFERENCES}

Archer, L. (2008), 'Younger academics' constructions of 'authenticity', 'success' and professional identity', Studies in Higher Education, 33 (4), 385-403.

Ballard, B. (1996), 'Context of judgement: an analysis of some assumptions identified in examiners reports on 62 successful $\mathrm{PhD}$ theses', paper presented at the Conference on Quality in Postgraduate Research, Adelaide, South Australia.

Basaran, S. (2009), 'The process of writing research articles in English and getting published: a case study', Sosyal Bilimler Dergisi, 8 (2), 371-84, accessed 27 June 2013 at http://www.academia.edu/565518/The_Process_ of_Writing_Research_Articles_in_English_and_Getting_Published_A_Case_ Study.

Becher, T. and P. Trowler (2001), Academic Tribes and Territories: Intellectual Enquiry and the Culture of Disciplines, 2nd edn, Buckingham: Society for Research into Higher Education (SRHE) and Open University Press.

Belcher, D.D. (2007), 'Seeking acceptance in an English-only research world', Journal of Second Language Writing, 16 (1), 1-22.

Burgess, S. and P. Martín-Martín (2008), English as an Additional Language in Research Publication and Communication, Bern: Peter Lang. 
JOBNAME: Fayolle \& Wright PAGE: 21 SESS: 4 OUTPUT: Tue Sep 24 08:30:12 2013

152 How to get published in the best entrepreneurship journals

Cho, S. (2004), 'Challenges of entering discourse communities through publishing in English: perspectives of nonnative-speaking doctoral students in the United States of America', Journal of Language, Identity and Education, 3 (1), 47-72.

Coimbra Group (2012), Survey on PhD Programme Structures and Administration in Europe and North America: Main Findings, accessed 11 April 2013 at http://www.coimbra-group.eu/transdoc/uploads/TRANS-DOC\%20Survey\%20 findings.pdf.

Day, N.E. (2011), 'The silent majority: manuscript rejection and its impact on scholars', Academy of Management Learning \& Education, 10 (4), 704-18.

Delamont, S. (2011), 'Academic writing in a global context: the politics and practices of publishing in English', Studies in Higher Education, 36 (4), $505-6$.

Fiske, D.W. and L. Fogg (1990), 'But the reviewers are making different criticisms of my paper! Diversity and uniqueness in reviewer comments', American Psychologist, 45 (5), 591-8.

Golde, C. (2010) 'Entering different worlds: socialization into disciplinary communities' in S.K. Gardner and P. Mendoza (eds), On Becoming a Scholar: Socialization and Development in Doctoral Education, Stirling, VA: Stylus, pp. 79-96.

Ivanic, R. (1998), Writing and Identity: The Discoursal Construction of Identity in Academic Writing, Amsterdam and Philadelphia, PA: John Benjamins B.V.

Lave, J. and E. Wenger (1991), Situated Learning: Legitimate Peripheral Participation, Cambridge, New York, Melbourne and Madrid: Cambridge University Press.

Larivière, V., A. Zuccala and É. Archambault (n.d.), 'The declining scientific impact of theses: implications for electronic thesis and dissertation repositories and graduate studies', accessed 11 April 2013 at http://individual.utoronto.ca/ azuccala_web/Larivier-et-al.pdf.

Neergaard, N., L. Tanggaard, N. Krueger and S. Robinson (2012), 'Pedagogical interventions in entrepreneurship from behaviourism to existential learning', conference proceedings, International Small Business and Entrepreneurship Conference, 7-8 November. Dublin, Ireland.

Park, C. (2005), 'New variant PhD: the changing nature of the doctorate in the UK', Journal of Higher Education Policy and Management, 27 (2), 189-207.

Pearson, M. (1996), 'Professionalising Ph.D. education to enhance the quality of the student experience', Higher Education, 32 (3), 303-20.

Smith, S. (2010), 'Beyond the dissertation monograph', accessed 11 April 2013 at http://www.mla.org/blog\&topic $=133$.

Thompson, J.W. (2002), 'The death of the scholarly monograph in the humanities? Citation patterns in literary scholarship', Libri, 52 (3), 121-36.

Walker, G.E, C.M. Golde, L. Jones, A.C. Bueschel and P. Hutchings (2008), The Formation of Scholars: Rethinking Doctoral Education for the Twenty-First Century, San Francisco, CA: Jossey-Bass.

Wallwork, A. (2011), English for Writing Research Papers, New York: Springer. 